\title{
Modelling an aquifer's response to a remedial action in Wadi Suq, Oman
}

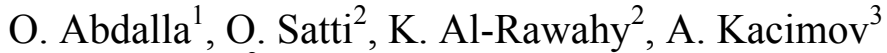 \\ \& H. Al-Zarie ${ }^{2}$ \\ ${ }^{I}$ Department of Earth Sciences, College of Science, \\ Sultan Qaboos University, Oman, UAE \\ ${ }^{2}$ Department of Petroleum and Chemical Engineering, \\ College of Engineering \\ ${ }^{3}$ Department of Soils and Water, College of Agriculture and Marine \\ Sciences, Sultan Qaboos University, Oman, UAE
}

\begin{abstract}
The present study simulates a predictive alluvium-aquifer's response to a proposed remedial action in the Wadi Suq area, Oman. Contamination due to copper mining and smelting, which was incepted in 1982 and ceased in 1993, has severely impacted the groundwater quality down the gradient. The major concern is the increase of salinity as abundant seawater has been used in mining. Saline plume of an average $35000 \mathrm{mg} / \mathrm{l}$ TDS has formed down the gradient from the dam site and spread towards the coast that represents a hydrogeologic boundary. The contaminated aquifer, in which groundwater flows for a path of $34 \mathrm{~km}$ to the coast, is composed of unconsolidated alluvium, predominantly gravels and sands in its upper part and of weathered ophiolite in its lower part. The massive fresh ophiolite represents the lower hydrogeologic boundary. Though lithologically different, the aquifer units have been simulated as one unit since the hydraulic properties are more or less similar.

Remedial efforts that had been carried out so far were deemed ineffective. The present study proposes a remediation measure by injecting freshwater via wells into the aquifers. Head and concentration values for the year 1993 were used as initial heads/concentrations for the steady flow simulation in which the computed heads/concentrations were matched with the observed ones, whereas transient flow runs were conducted to predict aquifer's response with time. Simulated aquifer response to the injection of freshwater indicates the reduction of TDS with time and the movement of the plume to eventually discharge into the Gulf of Oman. Consequently, the proposed remedial action, though financially challenging, is effectual.
\end{abstract}

Keywords: Oman, mining, Wadi Suq, MODFLOW, groundwater modelling. 


\section{Introduction and background}

Oman Mining Company (OMC) has launched large copper mining activities in 1980 in Wadi Suq, Sohar area, northern Oman. An unlined tailings dam, upstream of Wadi Suq, was founded in 1982 and followed in 1983 by the construction of a pipeline to transport seawater from the coast to the processing plant [1]. Copper was processed using flotation method and a total of 15000 tons of ore was mined annually. Ore processing and waste disposal of continued until 1994 to generate about 11 million tons of sulphide rich tailings. Since project's inception till the ban of the seawater usage in 1993, about $5 \mathrm{~mm}^{3}$ of seawater being disposed of in the tailings dam. Consequently, elevated salinity (high total dissolved solids (TDS)) has been observed in the groundwater down the gradient, $\mathrm{pH}$ changed and mobility of certain heavy metals increased. Although, the groundwater pollution was detected as early as 1983, mining activities continued and the situation worsened [1]. Several observation wells were installed down the gradient from the dam ( $>40$ wells) to monitor the pollution. Periodic and extensive sampling and analyses of water collected from the wells continue since the detection of the pollution in 1983 yielding a comprehensive hydrochemical database. Data collected included but not limited to measuring TDS, EC, concentration of major ions and trace elements. The pollution has severely impacted the smaller settlements in the region that were totally dependent on groundwater, which is no longer suitable for drinking or irrigation.

The area was the focal point of several studies carried out after the discovery of the pollution [1-4]. The main objectives of these studies were to assess and identify the extent of the pollution. Application of remediation techniques and evaluation of the currently taken measures were not assessed or studied. Therefore, the present study aims to shed some light on the remediation proposal and pollution cleanup. The present study simulates the aquifer response to a proposed remediation action. Injection of fresh water via wells in the upper catchment of the wadi is proposed to dilute and disperse the contaminants. The study models the groundwater flow and solute transport to predict the future aquifer response and to measure the validity of the proposal.

Wadi Suq is located in north Oman and is on the eastern side of the Hajar Mountains (fig 1A). The area is characterized by arid climate and variable topography. Highest elevation of about $300 \mathrm{~m}$ above sea level is reported in the mining site while the plain down towards the Gulf of Oman is a few meters above the sea level. The length of the Wadi is about $34 \mathrm{~km}$, travels towards the Gulf of Oman, at a slope of 0.008 and has a $70 \mathrm{~km}^{2}$ catchment area. The wadi is filled of Quaternary alluvium of unconsolidated sand and gravels. Highest elevation of about $300 \mathrm{~m}$ above sea level is reported in the mining site while the plain down to the coast is a few meters above the sea level.

In continuous remediation efforts and to contain the problem, OMC first constructed a cut off trench \#1 in 1983 right after the tailings dam. Groundwater was pumped from the trench and discharged into a lined evaporation pond to prevent further contaminants flow and to reduce the level of salinity. The pumped water is left in the pond for complete evaporation and solid residues are 
disposed of. Another trench "T2" was constructed in 1992 when the remediation results of $\mathrm{T} 1$ were not satisfactory. OMC has lately realized that seepage from tailings impoundment poses a great threat to the groundwater resources. Pollutants leach into groundwater subsequent to precipitation, especially storm events, will severely impact the quality of soil and groundwater. Consequently, the tailings were covered with lining to prevent further leaching and infiltration. To keep the $\mathrm{pH}$ at the desired level (ca 7) to prevent mobility of toxic and heavy metals, lime was added to the tailings to reduce the acidity of mine drainage.

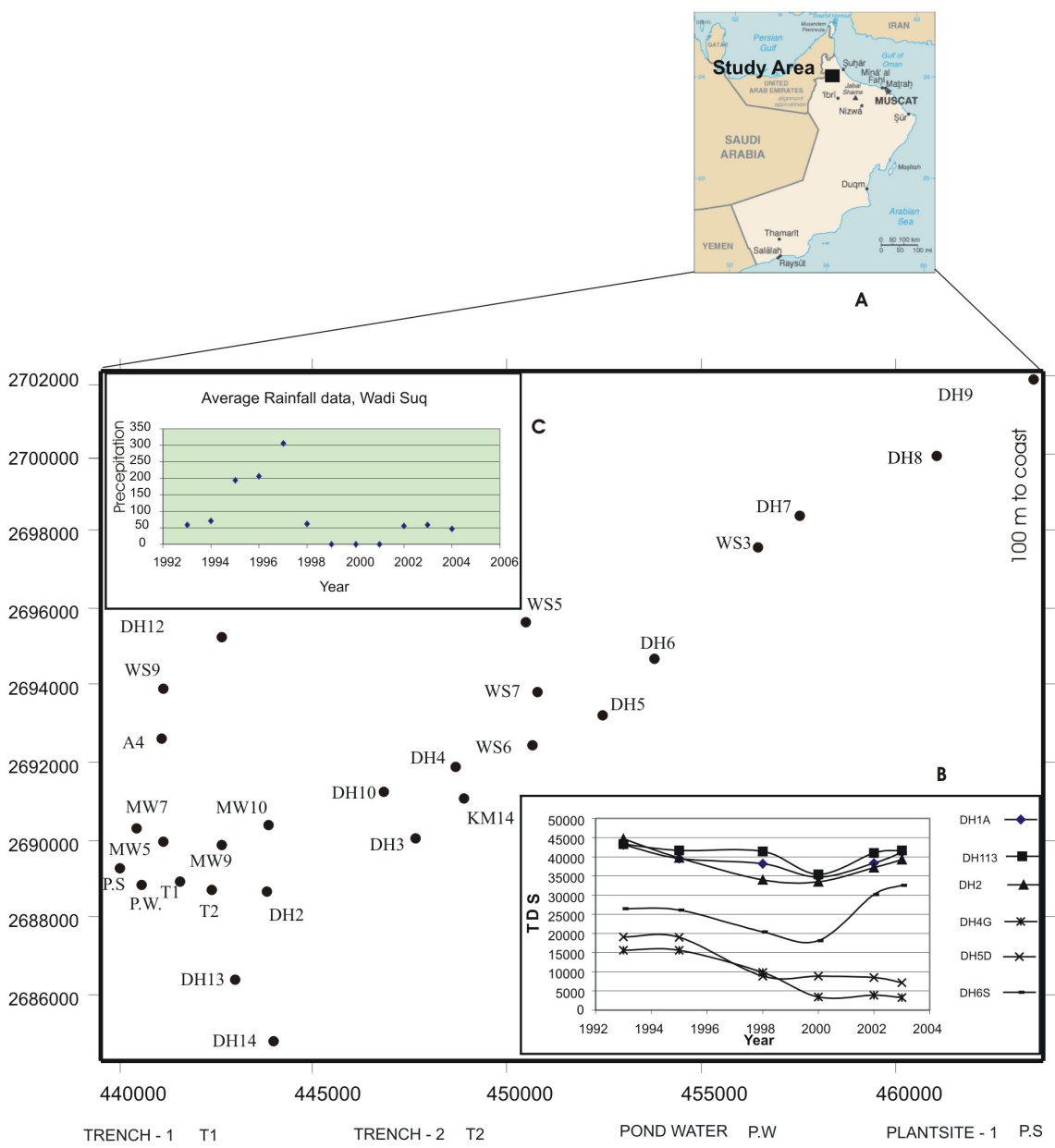

Figure 1: A-location map of representative monitoring wells. Location of the trenches and plant site is also indicated in the map. B- Measured TDS ppm for selected monitoring wells since 1993 to 2003. C-Average precipitation in Wadi Suq since 1993. High values occurred around 1995-1998. 


\subsection{Remediation approaches}

The remediation efforts that have been carried out thus far in Wadi Suq are ineffective. The approaches used are similar to pump and treat approach but differ in that water is left for evaporation; treated water is not pumped back to the aquifer. Taking into consideration that annual groundwater recharge is minimum; the quality of polluted groundwater if not worsens it will not improve. It is therefore expected that TDS and concentration of several ions remain either unchanged or fluctuating within similar ranges. Fig 1B shows the measure of TDS against time from selected wells in the area. The general trend shows a total decrease in salinity after 1998 and a rebound after 2002. This phenomenon is explained by a comparison with the total precipitation in the area (Fig 1C). The general trend of increasing/decreasing salinity observed in Fig 1B is correlated with the precipitation trend shown in Fig 1C. It can be clearly deduced from the figures that the reduction in the TDS was mainly due to the increase in annual rainfall, whereas the increasing observed salinity in the following years is attributed to the drought during these years. Thus, natural corrective action to the pollution problem has been observed and increasing rainfall will effectively lower the concentration of pollutants. Hence arose the current remediation proposal, which employs dilute and disperse approach to Wadi Suq area. The idea is to inject fresh water into the aquifer using artificial means; if toxic substances are sufficiently diluted they will be rendered harmless. On the other hand artificial recharge of groundwater from injection wells will increase the hydraulic gradient and the flow velocity and therefore enhance the plume movement by advective means. While the concentration of toxic substances is diluted, the plume will be moving towards the ocean (coast is $34 \mathrm{~km}$ from the site) and will eventually vanish. The dilute and disperse approach in the Wadi Suq can be proposed as:

-use the existing pipeline previously employed to transport water from the coast;

-use water from desalination plant/s on the coast;

-construct injection wells on the upper catchment;

-inject water of low TDS into the aquifer.

The cost of the above proposal is the minimum since the pipeline is already available and desalination plants are operating. The added cost will be for wells installation and the desalinated water. The average cost of the desalinated cubic meter in Oman ranges between 400-600 Piza (\$1.2-\$1.6). Currently potable water is transported to the households in the scattered settlements, the cost of which can be integrated with remediation cost.

\section{Modelling the hypothesis}

The proposed remediation action by injecting freshwater into the aquifer needs to be tested before implementation. The present study simulates aquifer's response to the remediation proposal and checks against the validity of the action. The model will use the USGS MODFLOW 2000 and go through the following steps. 


\subsection{Build the conceptual model}

The model is one layer case with an area of about $550 \mathrm{~km}^{2}$ subdivided into grids (22 rows and 46 columns). Grids are closely spaced at the site of the dam to enhance the accuracy of head and concentration calculation. Geology of the area is characterized by variable fracture systems running along and across the wadi whereas the subsurface lithology is simple and uniform. The quaternary alluvium that is composed mainly of gravels and sand comprises the main aquifer system. The alluvium layer occupies the upper section and thickens towards the Gulf of Oman. It is overlain by a thin layer of superficial deposits. Tertiary limestones reported at the peripheries of the wadi occasionally extend in form of lenses intermingle with the alluvium. These limestone lenses were described in a few drilling reports of the monitoring wells. The alluvium is unconformably overlying a sequence of ophiolite rocks (Semail Ophiolite) opducted during the Cretaceous. The ophiolite is composed of gabbroic and basaltic rocks, sheeted dykes, dunite and harzburgite. The copper mining is from the ophilitic rocks that are characterized by sulphide mineralization and rich in $\mathrm{Fe}$ and $\mathrm{Cu}$ in particular and $\mathrm{Al}, \mathrm{Mn}, \mathrm{Zn}, \mathrm{Pb}, \mathrm{Ni}, \mathrm{Cd}$ and $\mathrm{Cr}$ in general. The upper part of the ophiolite is highly weathered which enhances permeability and porosity. The hydraulic properties of the weathered ophilite are similar to that of the alluvium and therefore the two units are considered one hydrogeologoic unit.

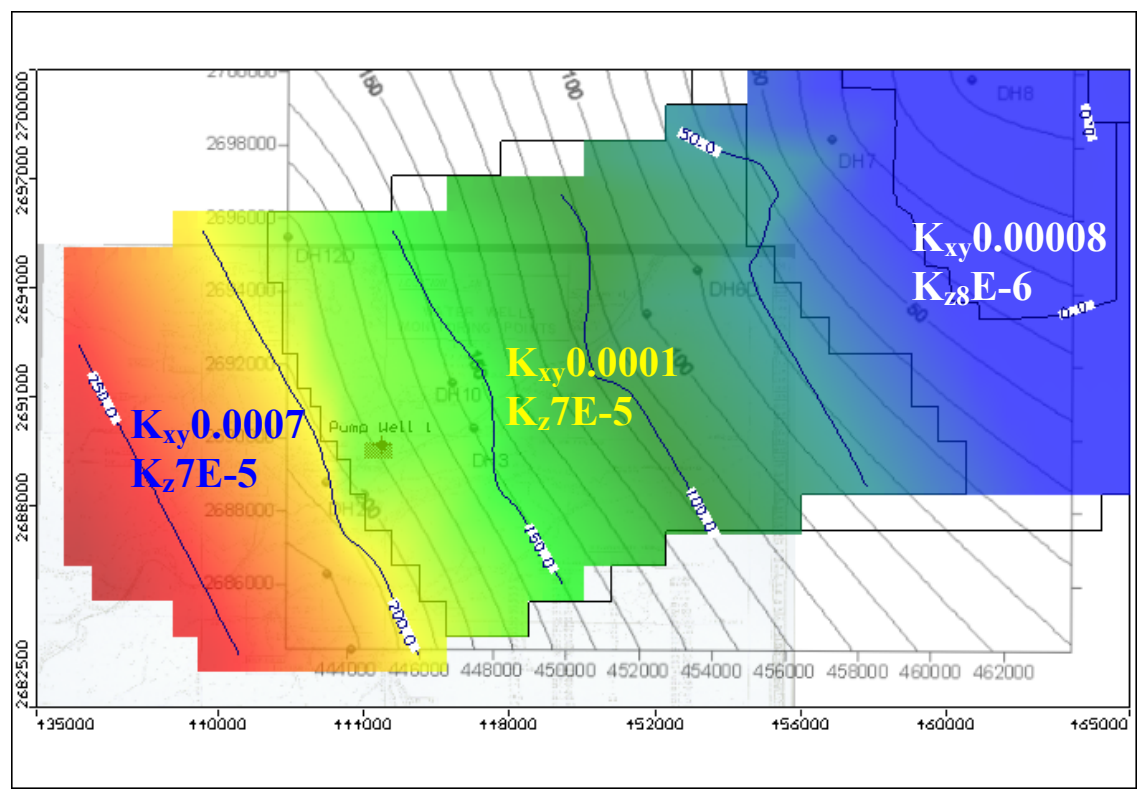

Figure 2: Computed head values after the steady state flow simulation matched with the observed head values in year 1993. 
Based on rainfall data and soil cover, $50 \mathrm{~mm} / \mathrm{year}$ is assigned to the upper catchment. Evapotranspiration $1100 \mathrm{~mm} /$ year is assumed throughout the study area with an effective depth of $10 \mathrm{~m}$. The model area is subdivided into 3 zones with reference to hydraulic conductivity $(\mathrm{K})$ value: the upper, middle and lower. The $\mathrm{K}$ values (Fig 2) decrease towards the coast as the fines increase. Constant head boundary $(\approx 0 \mathrm{~m})$ is assigned to the coastal zone. The aquifer is surrounded from the other 3 sides by crystalline impermeable igneous rocks and thus no flow boundary along these margins was assumed.

\subsection{Steady/transient simulation}

Head simulation for one day produced initial head values used in the transient run. Computed heads during this stage matched with the observation heads measured in the year 1993 (Fig 2). Simulation of flow and solute transport for the period 1993-2006 utilized these heads together with the initial concentrations of TDS measured in year 1993. Aquifer storage, bulk density and dispersion values were continuously readjusted till the best fit between the computed and observed concentrations/heads were in best match. This best match was achieved with the values: bulk density $=1700 \mathrm{~kg} / \mathrm{m}^{3}$, dispersion $=0.01$, specific storage $=0.0001$, specific yield $=0.08$, effective porosity $=0.08$ and total porosity $=0.15$.

\subsection{Predictive transient simulation}

The calibrated values obtained during the previous steady and transient runs are used in this simulation to predict aquifer's response to the injection of freshwater via wells for the period 2006-2016. Four injection wells next to the dam were proposed with time variant discharge $\left(1500-500 \mathrm{~m}^{3} / \mathrm{d}\right)$ to account for well loss and efficiency reduction with time. The injected water has an assumed average TDS of $500 \mathrm{mg} / 1$ which is the maximum expected for Oman desalinated water.

\section{Results and discussions}

The simulation has shown that the TDS plume migrates towards the coast with falling concentration (Fig 3). While the plume is moving with the advective transport at the speed of the groundwater, injected freshwater dilute the polluted groundwater and significantly reduces the TDS with time. The extent of the plume (TDS $>15000 \mathrm{ppm}$ ) will only be limited to a circle $>500 \mathrm{~m}$ diameter after 10 years of remediation. Only 4 wells were used during the current simulation with total discharge of $1500-500 \mathrm{~m}^{3} / \mathrm{d}$. Increasing the number of the wells and their discharge will exponentially decrease the time required for the cleanup. If more freshwater is added, the hydraulic gradient will increase and consequently speeds up the advective transport of the plume on one hand and dilute the concentration on the other. The mass balance simulation has also shown the significance of the proposed action in reducing the total mass of the solute in the aquifer (Fig 4). The total mass of solutes (sources in) that enter the system is much less than the total mass of the solutes (sinks out) that leave the 
system. About $10^{9} \mathrm{~kg}$ of mass will leave the system after 10 years of remediation.
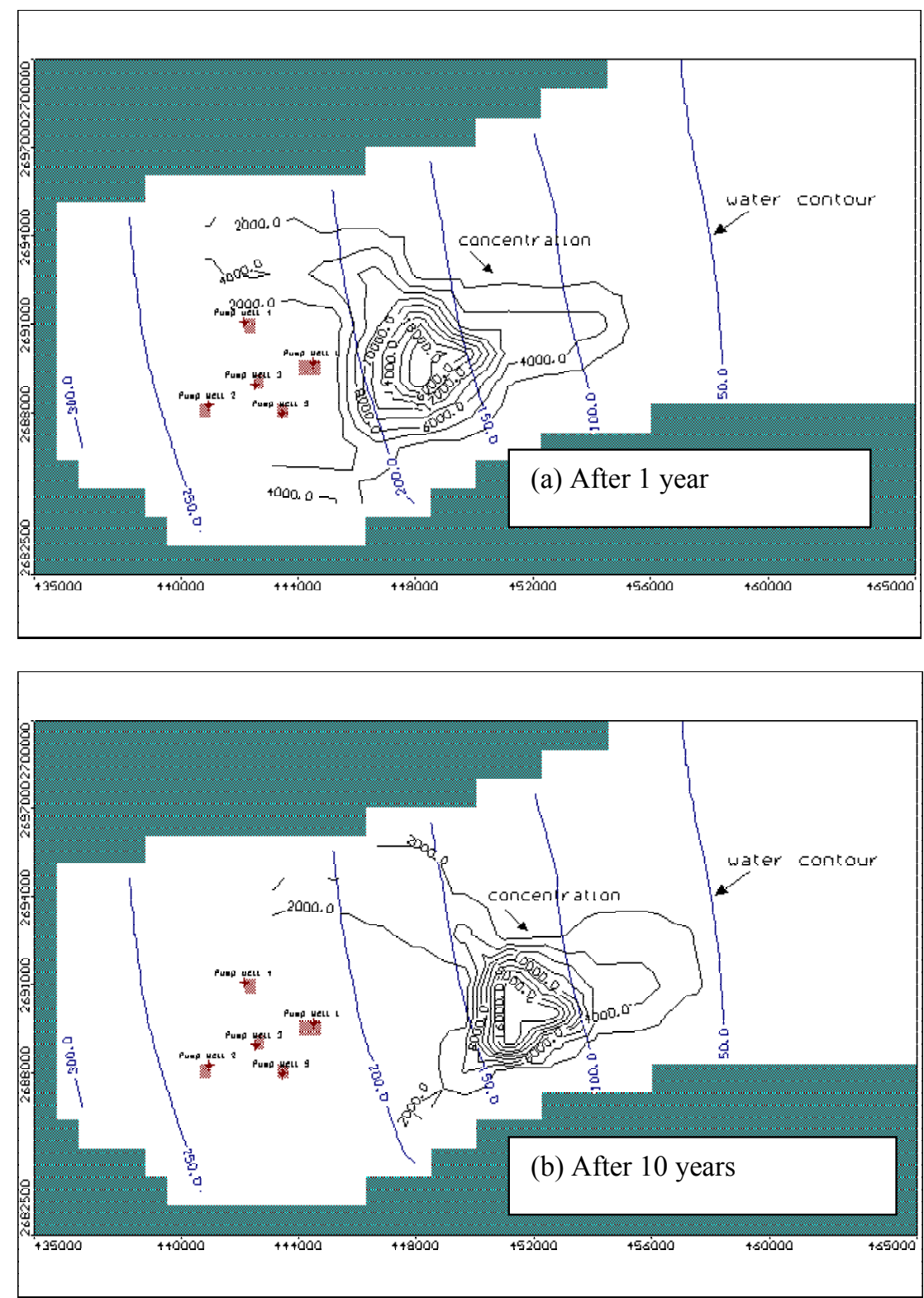

Figure 3: TDS plume moving towards the coast. The figure shows the concentration and plume location after one year of remediation (a) and 10 years of remediation (b). 
The above simulation, though applicable and effective, has significant shortcomings that need to be thoroughly considered before any future implementation. The area is characterized by faulting and fracturing systems that enhance the advective transport and also may lead to uncontrolled leakage from the aquifer into the country rocks. This leakage will cause unaccounted for pollution to presently cleaner areas. Conduits in form of faults and fractures should be precisely identified and sealed before the injection of freshwater. Moreover, an estimate of dispersion as a non-measurable parameter adds uncertainty to the computation. The proposed action will on the contrary provide recharge to replenish the ever since depleting groundwater resources, reduce the toxicity in the region, revive the farms and agricultural activities, relief the financial burden of transporting water supplies to locals and before all cleanup the toxic environment.

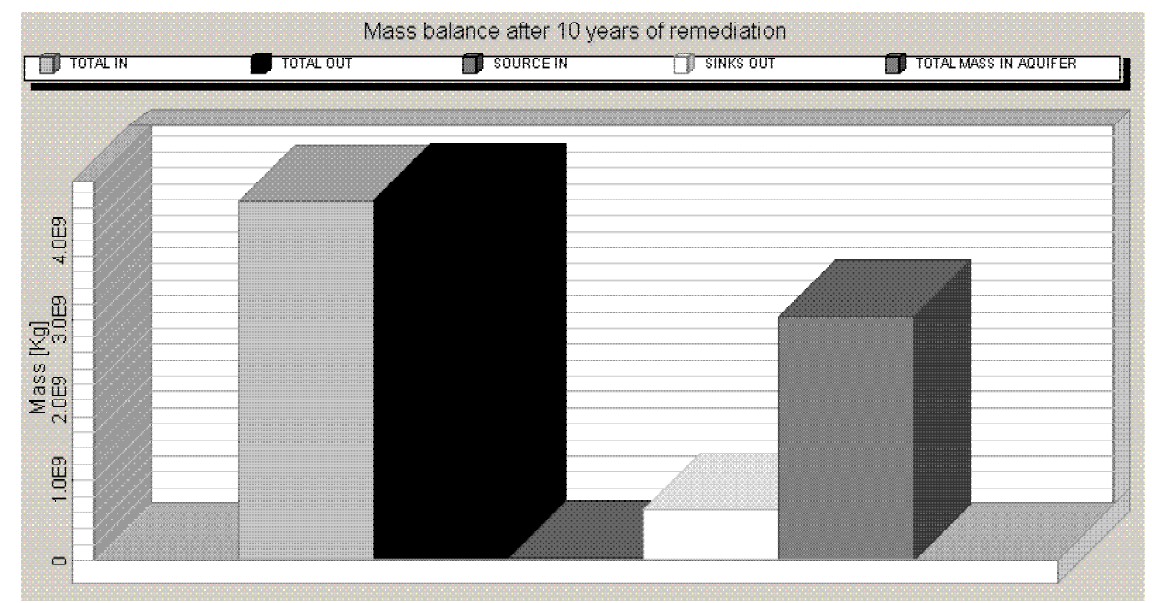

Figure 4: Mass balance after 10 years of remediation.

\section{Conclusions}

The current simulation has indicated that the total mass of the solutes in the alluvium aquifer of Wadi Suq will reduce significantly with time. The proposed remediation action will provide source of aquifer recharge in addition to the cleanup of the environmental problem. As the infrastructure is already available, injecting water into the aquifer is economically feasible.

\section{Acknowledgements}

The authors would like to thank Sultan Qaboos University for providing financial support under the HM project \#SR/ENG/PMRE/02/01. Thanks are also due to OMC and the MWR for providing the data. 


\section{References}

[1] Ministry of Water Resources, Sultanate of Oman (MWR). 1996. Groundwater Pollution and Remediation in Wadi Suq. Ministry of Water Resources, Muscat, Oman.

[2] Japan International Cooperation Agency (JICA) and Ministry of Commerce and Industry, Oman. 2001. The Feasibility Study on Mine Pollution Control in Sohar Mine Area, Sultanate of Oman (Final Report). Mitsubishi Materials Natural Resource Development Corp, E \& E Solutions Incorporation, Japan.

[3] Sharma, R.S and Al-Busaidi, T.S. 2001. Groundwater pollution due to a tailings dam. Engineering Geology 60, 235-244.

[4] Satti, O.; AlRawahi, K.; Kacimov, A.; Abdalla, O. and Al-Zarie H. 2006. Mining related groundwater contamination and its impact on land usability at Wadi Suq, northern Oman. The International Conference on Economic Incentives \& Water Demand Management, Sultan Qaboos University, (CAMS), Muscat 18-22 March. 